\title{
Impact of Feed-in Generation in Market Prices and Calibration of a Capacity Term to Pay to Traditional Generation - Application to the Iberian Market
}

\author{
Adelino J. C. Pereira \\ Instituto Superior de Engenharia de Coimbra \\ Instituto Politécnico de Coimbra, Coimbra, Portugal \\ ajcp@isec.pt
}

\begin{abstract}
In this paper we describe the models and the simulations that were conducted in order to access the impact of feed-in subsidized generation in the market price in Portugal in the context of the Iberian Electricity Market. In Portugal and Spain feed-in generation (namely wind power) has a large share both in terms of installed capacity and generated energy and the presence of this energy in the hourly balance originates the reduction of the market price and of the number of hours during which traditional generation (namely coal and CCGT stations) are scheduled. This paper aims at evaluating this impact both in the short term (using the real market curves) and in the long term (using a long term generation expansion planning model). The paper includes results for the Iberian power system currently having a total installed capacity above $120 \mathrm{GW}$ and a total demand of 310 TWh by the end of 2013.
\end{abstract}

Index Terms-- electricity markets, impact of feed in generation, long term, generation expansion planning

\section{INTRODUCTION}

For the last twenty years several countries have adopted policies to induce investments in renewable generation (namely wind parks, small hydros's, photovoltaic's and biomass units) and in non-renewable units as cogeneration. Among the most successful countries towards this objective, Portugal and Spain increased this type of capacity to 6000 MW out of $18000 \mathrm{MW}$ in Portugal and to $35000 \mathrm{MW}$ out of 102000 MW in Spain. Regarding the generation, in Portugal it corresponded to a value close to $40 \%$ in 2012 (from which $25 \%$ from wind parks) while in Spain it reached $38 \%$ of the total (from which $20 \%$ from wind parks) not including the generation from large hydro stations.

As its legal designation suggests, the huge capacity increase of Special Regime Generation, SRG, is certainly due to the particular rules that were adopted to pay the generation from these units. In Portugal the first legislation to frame the operation of these units was passed in 1988 and it currently corresponds to a feed-in mechanism that includes avoided investment and operation cost terms and an environmental technology dependent term. to prize cleaner or still less

\author{
João Tomé Saraiva \\ Dept. de Engenharia Eletrotécnica e Computadores da FEUP \\ INESC Porto, Porto, Portugal \\ jsaraiva@fe.up.pt
}

mature technologies. As a result, the average price paid to wind parks is currently close to $80 € / \mathrm{MWh}$ and is above 200 €/MWh to small photovoltaic units. In Spain SRG generation can opt between a regulated feed-in tariff or receiving the market price plus a percentage of a regulated reference value.

The impact of such large volumes of SRG is very important, namely considering that the average price in the day ahead market common to Portugal and Spain is in well below the feed in tariff levels, namely for wind. For example, in 2012 the average market price was $48 € / \mathrm{MWh}$ and the prices in both countries were very close indicating that congestion in the interconnection lines was rare (in fact, less than $15 \%$ of the hours in 2012). Although not being paid the hourly market price, SRG has to be considered in the clearing because it contributes to balance the supply and the demand. In practice, zero price segments are added to the selling bid curve corresponding to the estimated hourly SRG. As a result, when SRG is large (typically in windy and rainy periods) the market prices decline and less traditional thermal generators are cleared. This ultimately means that the total number of hours these thermal generators operate has been declining thus reducing the income of these generation agents.

Given these issues, it becomes important to estimate the impact of SRG in market prices to evaluate the revenues of existing generators and also to adequately build generation expansion plans. Accordingly this paper describes and presents results regarding this impact considering two ways:

- in the first place, we used the real aggregated selling and buying curves for the Iberian Market to recalculate the market price eliminating the segments associated with the total SRG generation and also with wind generation;

- secondly, we used the long term dynamic generation expansion model in $[1,2]$ to estimate the evolution of the market price admitting several scenarios for the wind power installed capacity. Using 2010 as the reference year and a 15 year horizon, we simulated four cases as follows: elimination of the existing wind power capacity, reduction of this capacity by $50 \%$, increase of the wind power installed capacity by $25 \%$ and by $50 \%$. 


\section{ANALYSIS OF THE IMPACT OF SRG USING MARKET CURVES}

As mentioned before, SRG generation must be considered when building the aggregated hourly market curves in order to balance the global demand and generation. This is done including in the selling aggregated curve segments at zero price having quantities based on estimates for each hour of the next day for the generation of each SRG technology. It is therefore clear that in periods in which SRG generation is large the selling bid curve from other generation agents shifts to the right side and so the market price gets reduced. On the contrary, if wind generation (the most relevant SRG) is small then the electricity price increases and more thermal selling bids are accepted. If a very windy period occurs together with large hydro inflows (as it is typical in November till March/April) then market prices have sharp declines and can continuously be at $0 € / \mathrm{MWh}$ for several hours.

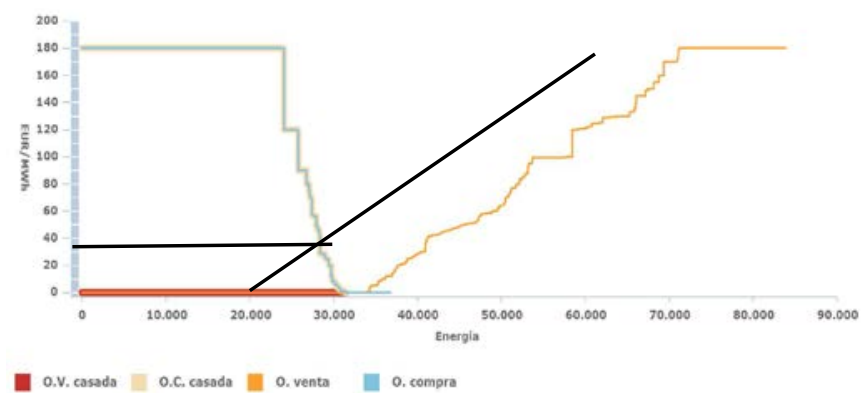

Figure 1. Aggregated selling and buying curves for the Iberian electricity market for hour 1 of March 12, 2013.

Figure 1 illustrates this impact showing the selling and buying curves for hour 1 of March 12 2013. At this hour the market price was $0.0 € / \mathrm{MWh}$ as a result of the intersection of the buying (blue) and selling (red) curves. The $0.0 € / \mathrm{MWh}$ selling segment amounts to $32000 \mathrm{MWh}$ resulting from about $7000 \mathrm{MWh}$ from nuclear stations, $10000 \mathrm{MWh}$ from hydro stations and $12000 \mathrm{MWh}$ from wind parks. If this 12000 MWh segment was not present, then the selling curve would shift to the left (black line) and so the market price would increase from 0.0 to $38 € / \mathrm{MWh}$. The 0.0 price segment also reduces the number of accepted bids from thermal generators. Thus, the income obtained by thermal stations is reduced not only because the market price reduces but also because the number of hours they are dispatch gets smaller.

Using this approach, we evaluated the impact of SRG, in general, and wind power, in particular, during December 2012, following the next steps for each hour of this month:

i. the data regarding the submitted selling and buying bids was downloaded from the web page of the Iberian Market Operator. These values were used to build the selling and buying curves for each analyzed hour;

ii. then, we eliminated from each selling curve the total SRG generation and obtained the new crossing between the modified selling curve and the buying curve that remains unchanged regarding the one built in step $i$. The crossing between these two curves gives the new clearing price for the hour under analysis;

iii. finally, the above procedure was repeated eliminating wind power generation. The crossing between the modified selling curve and the original buying curve leads to the clearing price without wind generation.

The above procedure was used to analyze the entire month of December 2012 as detailed in Section V. However, it is clear that a similar approach can be adopted to evaluate the impact of each SRG technology provided that data for the hourly generation of each technology is available.

\section{GENERATION EXPANSION PLANNING}

\section{A. Overview on Generation Expansion Planning, GEP}

Generation Expansion Planning, GEP, has long been a matter of concern and analysis at the academic and industrial levels. Before the restructuring process through which the electricity sector went, GEP was addressed in an integrated way together with the expansion and reinforcement planning of transmission networks. This was traditionally modeled using integer variables as [3]. On the other hand, the inclusion of uncertainties led to the adoption of stochastic optimization to represent alternative investment decisions as in [4].

Still under the vertically integrated paradigm, several authors recognized that GEP should address several criteria as the investment and the operation costs, environmental impacts, risk aspects as well as the adequacy of the system to meet the demand $[5,6]$. One the reasons leading to the complexity of GEP is related with the integer nature of investment decisions. This justified the use of several metaheuristic techniques as a way to identify good quality multi period investment decisions for a very complex problem as it is documented in $[7,8,9,10]$ using Genetic Algorithms, Simulated Annealing, Neural Networks and Expert Systems.

More recently, the advent of electricity markets changed power systems in several countries not only regarding shorter term operation planning but also in terms of long term activities. Regarding long term expansion planning, these changes are related with the fact that the integrated utilities were segmented and generation was decoupled from transmission, that the generation subsector was segmented itself originating several competing companies and thirdly GEP was always a risky activity because it was based on expectations regarding the long term evolution of the demand, of the economic growth and of fuel prices. Electricity markets increased the risk and it is favoring shorter term investment decisions and less capital intensive investments.

Given the complexity of the GEP problem, the presence of several competing generation agents, the existence of inter dependencies and feedback loops between the electricity price, the demand and the investment decisions, System Dynamics started to be use in this problem. System Dynamics was introduced by J. Forrester [11] to model the evolution of complex systems providing a powerful tool to consider interdependencies between different parts of the system and how past and present decisions impact on its future behavior. Since then several applications of System Dynamics to the GEP problem were developed as in $[12,13,14]$.

\section{B. GEP Using a System DynamicsModel}

The developed GEP approach starts with a set of initial input electricity prices, $\pi^{\mathrm{t}}$, and capacity factors for each 
technology for each period, $\alpha_{t}^{\mathrm{ij}}$. These initial values are used by each GENCO to prepare their own investment plans. These individual plans are used to update the generation installed capacity and then the dynamic simulation is run to adjust the electricity prices and the capacity factors. This defines an iterative process that ends if after two successive iterations the individual investment plans display no changes. For a particular set of prices and capacity factors, each GENCO builds its expansion plan solving the mixed integer problem (1-7). This problem maximizes the profit obtained by each GENCO by selling electricity while taking into account investment and operation costs. The second term in (1) is related with a capacity payment to remunerate GENCOs for investments that eventually have a small number of operation hours but that contribute to improve the security of the system.

$\max z=\sum_{t=1}^{T}\left[\begin{array}{l}\sum_{j=1}^{M} \pi^{\mathrm{t}} \cdot C C_{t}^{\mathrm{ij}} \cdot \Delta \mathrm{t} \cdot \alpha_{\mathrm{t}}^{\mathrm{ij}}+\sum_{\mathrm{j}=1}^{\mathrm{M}} \mathrm{P}_{\mathrm{cap}}^{\mathrm{j}} \cdot C C_{\mathrm{t}}^{\mathrm{ij}} \cdot\left(1-\alpha_{\mathrm{t}}^{\mathrm{ij}}\right)- \\ \sum_{\mathrm{j}=1}^{\mathrm{M}} \operatorname{Cinv}_{\mathrm{t}}^{\mathrm{j}} \cdot \mathrm{X}_{\mathrm{t}}^{\mathrm{ij}}-\sum_{\mathrm{j}=1}^{\mathrm{M}} \operatorname{Cop}_{\mathrm{t}}^{\mathrm{j}} \cdot C C_{\mathrm{t}}^{\mathrm{ij}} \cdot \Delta \mathrm{t} \cdot \alpha_{\mathrm{t}}^{\mathrm{ij}}\end{array}\right]$

subj

$$
\begin{array}{ll}
X_{t}^{i j} \leq M_{t} C_{t}^{i j} & \text { for each } t, \text { for each } j \\
\sum_{j=1}^{M} X_{t}^{i j} \leq M^{2} C_{t}^{i} & \text { for each } t \\
\sum_{j=1}^{M} X_{t}^{i j} \cdot \operatorname{Cinv}_{t}^{j} \leq M X I N V_{t}^{i} & \text { for each } t \\
\sum_{t=1}^{T} \sum_{j=1}^{M} X_{t}^{i j} \cdot \operatorname{Cinv}_{t}^{j} \leq M X I N V^{i} & \\
C C_{t}^{i j j}=C_{t-1}^{i j j}+X_{t}^{i j} & \text { for each } t, \text { for each } j \\
t=1, \ldots ., T ; i=1, \ldots ., N ; j=1, \ldots ., M
\end{array}
$$

\begin{tabular}{|c|c|}
\hline$t$ & - stage in the planning horizon; \\
\hline $\mathrm{T}$ & - number of stages in the planning horizon; \\
\hline$\Delta \mathrm{t}$ & - duration in hours of each stage; \\
\hline $\mathrm{j}$ & type of candidate expansion technology; \\
\hline M & - number of candidate technologies; \\
\hline I & - index associated to a particular GENCO; \\
\hline $\mathrm{N}$ & - number of GENCO’s; \\
\hline $\mathrm{P}_{\text {cap }}^{\mathrm{j}}$ & $\begin{array}{l}\text { - capacity payment set for technology j, } \\
\text { (€/MW); }\end{array}$ \\
\hline $\operatorname{Cinv}_{t}^{j}$ & $\begin{array}{l}\text { - investment cost of technology } \mathrm{j} \text { at stage } \mathrm{t} \text {, } \\
(€ / \mathrm{MW}) \text {; }\end{array}$ \\
\hline $\operatorname{Cop}_{\mathrm{t}}^{\mathrm{j}}$ & $\begin{array}{l}\text { variable operation and maintenance cost for } \\
\text { technology } \mathrm{j} \text { at stage } \mathrm{t},(€ / \mathrm{MWh}) \text {; }\end{array}$ \\
\hline $\mathrm{CC}_{\mathrm{t}}^{\mathrm{ij}}$ & $\begin{array}{l}\text { - cumulative capacity installed in stage } \mathrm{t} \text { for } \\
\text { GENCO i, (MW); }\end{array}$ \\
\hline$X_{t}^{i, j}$ & $\begin{array}{l}\text { - capacity addition of technology } \mathrm{j} \text { in stage } \mathrm{t} \\
\text { by GENCO } \mathrm{i},(\mathrm{MW}) \text {; }\end{array}$ \\
\hline $\mathrm{MIC}_{\mathrm{t}}^{\mathrm{ij}}$ & $\begin{array}{l}\text { - upper bound set for the installed capacity of } \\
\text { technology } \mathrm{j} \text { in stage } \mathrm{t} \text { by GENCO } \mathrm{i},(\mathrm{MW}) \text {; }\end{array}$ \\
\hline $\mathrm{MIC}_{\mathrm{t}}^{\mathrm{i}}$ & $\begin{array}{l}\text { - maximum capacity that can be installed in } \\
\text { stage } t \text { by GENCO i, (MW); }\end{array}$ \\
\hline $\mathrm{KINV}_{\mathrm{t}}$ & maximum value snecified for th \\
\hline
\end{tabular}

In this formulation: of GENCO $i$ at stage $t,(€)$;

$M_{X I N V}{ }^{i}$ - maximum investment of GENCO $i$ along the horizon $\mathrm{T}$, (€).

Regarding the constraints, (2) limits the capacity of technology $\mathrm{j}$ to install by GENCO $\mathrm{i}$ and (3) limits the total capacity to install by GENCO $\mathrm{i}$ in each period. Constraint (4) limits the investment cost of GENCO i per period and (5) limits the total investment along the entire horizon. Finally, (6) is used to update the installed capacity by GENCO $\mathrm{i}$.

This is a mixed integer optimization problem given the discrete nature of the $X_{t}^{i, j}$ decision variables. Each candidate technology is then characterized by a number of values as the investment cost, lifetime and construction time, fixed and variable operation costs and possible capacity values to be installed. Given the combinatorial nature of this problem, a Genetic Algorithm was used to solve it as described in [2].

Using the results of the problem (1-7) for each GENCO together with an initial estimated evolution of the demand, a number of global conditions are evaluated to check the quality of the global plan. Although different conditions reflecting regulatory or legal issues specific for each country can be used, the developed approach includes the following global constraints: the LOLE for each year of the horizon should be smaller than a specified limit, the reserve margin of the installed capacity regarding the peak power in each year should be larger than a specified limit and the share of the installed capacity of any GENCO should not exceed a specified threshold as a way to prevent market power.

Using the indications from this global check, together with the results of the profit maximization problems, the Dynamic Model is used to update the evolution of the demand, of the electricity prices and the capacity factors of the technologies in the generation mix. The capacity is obtained using the generation mix in the initial year adding the commissioned capacities obtained from the problems (1-7) and eliminating the capacities to be decommissioned. The main sub models of this Dynamic Model are related with the generation system, the evolution of the demand rate and the demand itself and the evolution of the electricity price. The generation system includes different technologies depending on the system to analyze. For Special Regime Generation, SRG, run of river and reservoir hydro stations, we used capacity factors based on historical data to obtain the generation for each period in the horizon. Then the difference between the estimated demand and the generation allocated to SRG and hydro stations is assigned to the thermal stations based on their operation costs. The generated power is then summed and this total is multiplied by a preset coefficient to include an estimate of network losses. The dynamic model includes a loop representing the interrelation between the price, the demand and the generation. This loop uses the annual load growth obtained in the upper left part of the model. Based on these values and on the elasticity of the demand to the price, it is obtained the demand evolution and finally using the generation costs and demand values it is obtained the price. This dynamic model is translated in a set of differential equations detailed in [2] that are solved using the Powersim software package for an hour integration step [15]. 


\section{RESULTS FOR DECEMBER 2012}

In the first place, we used the hourly market curves from the Iberian Market Operator for December 2012 to recalculate the market prices in the two following situations: eliminating the total SRG generation that existed in each trading hour and eliminating only the wind power generation. Table I details the results obtained for each hour of the $10^{\text {th }}$ of December 2012 given this was the day of this month having the smallest share of SRG. This Table has the values of the market price obtained by the Iberian Market Operator and the estimated prices not considering the total SRG, on one hand, and the wind generation on the other. In average, in December $10^{\text {th }}$ the market price was $58.55 € / \mathrm{MWh}$ and increased to 59.17 $€ / \mathrm{MWh}$ if the Portuguese wind generation was not considered and to $63.48 € / \mathrm{MWh}$ if no Portuguese SRG was considered.

TABLE I. MARKET PRICE AND ESTIMATEd PRICE WITHOUT THE TOTAL SRG AND WIND GEENERATION FOR $10^{\mathrm{TH}}$ OF DECEMBER 2012 (IN €/MWh)

\begin{tabular}{|c|c|c|c|c|c|c|c|}
\hline hour & $\begin{array}{c}\text { market } \\
\text { price }\end{array}$ & $\begin{array}{c}\text { price } \\
\text { without } \\
\text { SRG }\end{array}$ & $\begin{array}{c}\text { price } \\
\text { without } \\
\text { wind }\end{array}$ & hour & $\begin{array}{c}\text { market } \\
\text { price }\end{array}$ & $\begin{array}{c}\text { price } \\
\text { without } \\
\text { SRG }\end{array}$ & $\begin{array}{c}\text { price } \\
\text { without } \\
\text { wind }\end{array}$ \\
\hline 1 & 54.99 & 58.96 & 55.33 & 13 & 63.07 & 67.77 & 63.35 \\
\hline 2 & 49.75 & 54.21 & 50.04 & 14 & 61.86 & 66.66 & 62.06 \\
\hline 3 & 43.00 & 48.20 & 43.42 & 15 & 61.86 & 66.63 & 62.07 \\
\hline 4 & 41.83 & 47.34 & 42.26 & 16 & 59.50 & 64.51 & 59.94 \\
\hline 5 & 41.10 & 46.27 & 41.41 & 17 & 59.01 & 64.03 & 59.75 \\
\hline 6 & 42.59 & 47.85 & 42.86 & 18 & 63.25 & 68.25 & 64.32 \\
\hline 7 & 50.00 & 55.21 & 50.27 & 19 & 69.13 & 74.16 & 70.52 \\
\hline 8 & 58.68 & 64.05 & 59.57 & 20 & 70.13 & 74.90 & 71.28 \\
\hline 9 & 63.00 & 67.60 & 63.16 & 21 & 70.08 & 74.98 & 71.24 \\
\hline 10 & 64.05 & 68.65 & 64.27 & 22 & 70.13 & 75.09 & 71.42 \\
\hline 11 & 63.69 & 68.63 & 64.03 & 23 & 66.30 & 71.11 & 67.55 \\
\hline 12 & 60.69 & 65.56 & 61.00 & 24 & 57.50 & 62.90 & 59.06 \\
\hline
\end{tabular}

TABLE II. AVERAge Market Price AND Estimated Price Without the TOTAL SRG AND WIND GENERATIONS FOR DECEMBER 2012 (IN €/MWh)

\begin{tabular}{|c|c|c|c|c|c|c|c|}
\hline day & $\begin{array}{c}\text { market } \\
\text { price }\end{array}$ & $\begin{array}{c}\text { price } \\
\text { without } \\
\text { SRG }\end{array}$ & $\begin{array}{c}\text { price } \\
\text { without } \\
\text { wind }\end{array}$ & day & $\begin{array}{c}\text { market } \\
\text { price }\end{array}$ & $\begin{array}{c}\text { price } \\
\text { without } \\
\text { SRG }\end{array}$ & $\begin{array}{c}\text { price } \\
\text { without } \\
\text { wind }\end{array}$ \\
\hline 1 & 48.82 & 62.48 & 57.89 & 17 & 50.67 & 59.83 & 53.77 \\
\hline 2 & 49.16 & 58.57 & 53.52 & 18 & 52.08 & 61.66 & 56.41 \\
\hline 3 & 56.84 & 64.53 & 59.90 & 19 & 50.04 & 62.96 & 57.39 \\
\hline 4 & 48.44 & 63.54 & 58.28 & 20 & 37.16 & 57.61 & 49.59 \\
\hline 5 & 48.80 & 57.88 & 52.80 & 21 & 31.33 & 57.72 & 45.25 \\
\hline 6 & 52.82 & 65.16 & 60.39 & 22 & 37.49 & 52.42 & 43.36 \\
\hline 7 & 51.80 & 60.18 & 54.93 & 23 & 28.70 & 64.86 & 51.46 \\
\hline 8 & 48.12 & 58.15 & 52.61 & 24 & 14.49 & 50.98 & 38.67 \\
\hline 9 & 54.02 & 63.33 & 58.36 & 25 & 10.99 & 24.75 & 19.37 \\
\hline 10 & 58.54 & 63.47 & 59.17 & 26 & 27.10 & 39.99 & 31.84 \\
\hline 11 & 64.13 & 70.45 & 66.07 & 27 & 34.40 & 46.40 & 37.87 \\
\hline 12 & 67.49 & 73.08 & 69.09 & 28 & 42.46 & 60.26 & 51.36 \\
\hline 13 & 52.60 & 69.77 & 64.42 & 29 & 20.23 & 44.49 & 35.97 \\
\hline 14 & 41.69 & 85.30 & 74.92 & 30 & 35.25 & 45.67 & 38.68 \\
\hline 15 & 37.14 & 90.60 & 75.39 & 31 & 32.84 & 54.71 & 45.57 \\
\hline 16 & 22.36 & 55.99 & 45.78 & & & & \\
\cline { 1 - 4 } & & & & & &
\end{tabular}

On the other hand, the $14^{\text {th }}$ of December has the largest share of SRG generation. The average market price was 41.77 $€ / \mathrm{MWh}$ and increased to $74.93 € / \mathrm{MWh}$ not considering Portuguese wind generation and to $85.31 € / \mathrm{MWh}$ without all the Portuguese SRG. It is worth mentioning that in December $14^{\text {th }}$, the share of the Portuguese SRG wind generation was about $10.9 \%$ and the share of the Portuguese total SRG generation was $14.6 \%$ regarding the total traded energy in the Iberian electricity market. Finally, Table II displays the aggregated results for each day of December 2012. This Table the average daily price and the price not considering the total SRG and wind generations.

\section{RESULTS FOR THE HORIZON TILL 2025}

\section{A. Data of the Iberian generation system}

The second set of simulations used the long term GEP model that was described in Section III.B. Using this model and taking the year of 2010 as reference, we considered a 15 year horizon and ran a number of simulations to estimate the impact of wind generation on the average market price since this is the most significant SRG technology. Regarding December 2010 the generation mix in the Iberian Peninsula is given in Table III together with the values of the Forced Outage Rates, FOR, of coal and CCGT plants.

TABLE III. INSTALlED CAPACITIES IN PORTUGAL AND SPAIN (MW)

\begin{tabular}{|l|c|c|c|c|}
\hline Technologies & $\begin{array}{c}\text { Installed } \\
\text { capacity in } \\
\text { Portugal }\end{array}$ & $\begin{array}{c}\text { Installed } \\
\text { capacity } \\
\text { in Spain }\end{array}$ & $\begin{array}{c}\text { Total } \\
\text { Installed } \\
\text { Capacity }\end{array}$ & FOR \\
\hline Nuclear & 0 & 7777 & 7777 & - \\
\hline Coal_1 & 1184 & 7584 & 8768 & 0.02 \\
\hline Coal_2 & 592 & 3796 & 4388 & 0.02 \\
\hline Fuel/Gas, gasoil & 1877 & 2860 & 4737 & 0.02 \\
\hline CCGT_1 & 2550 & 16820 & 19370 & 0.02 \\
\hline CCGT_2 & 1279 & 8415 & 9694 & 0.02 \\
\hline Reservoirs & 2288 & 10537 & 12825 & - \\
\hline Run-of-river & 2290 & 7024 & 9314 & - \\
\hline Wind parks & 3705 & 19710 & 23415 & - \\
\hline Small hydros & 410 & 2035 & 2445 & - \\
\hline Other ren. & 122 & 4942 & 5064 & - \\
\hline
\end{tabular}

Regarding SRG, hydro and nuclear units we assumed that the capacity factors already reflect the availability of the primary resource as well as outage and maintenance periods. The Portuguese and the Spanish systems had installed capacities of 17995 and of $98687 \mathrm{MW}$ and the total demand was $52204 \mathrm{GWh}$ and $260530 \mathrm{GWh}$. The remaining data was taken from [1, 2] namely regarding: the installed capacity owned by each of the six generation companies that were considered, the capacity factors that were assigned to several technologies, for instance nuclear stations, run of river and reservoir hydro stations, commissioning and decommissioning plans, the evolution of the demand along the horizon, the candidate technologies and financial limitations imposed to the generation companies.

\section{B. Results for a 15 year planning horizon}

In the first place, the dynamic model was run to obtain a reference expansion plan and an estimate of the average market price along the 15 year horizon. Starting at 2010, Table IV details the expansion plans obtained for GENCO's 1 to 4 and Figure 6 shows the evolution of the yearly average electricity price. These plans include a total of $7600 \mathrm{MW}$ new capacity, from which $50.0 \%$ from Tech_1, $28.9 \%$ from Tech_2 and $21.1 \%$ from Tech_3. Tech_1 has the most 
reduced operation cost and its installed capacity was not even larger because the share of each technology was limited to $50 \%$. Finally, the average electricity market price was 51.7 $€ / \mathrm{MWh}$ along the horizon.

TABLE IV. REFERENCE CASE - EXPANSION PLAN FOR GENCO_1.

\begin{tabular}{|c|c|c|c|c|}
\hline GENCO & Year & Tech_1 (MW) & Tech_2 (MW) & Tech_3 (MW) \\
\hline \multirow{3}{*}{1} & 1 & 400 & 300 & 200 \\
\cline { 2 - 5 } & 2 & 400 & 200 & 200 \\
\cline { 2 - 5 } & 11 & 200 & - & 200 \\
\hline \multirow{3}{*}{2} & 1 & 400 & 300 & - \\
\cline { 2 - 5 } & 6 & 400 & 300 & 200 \\
\cline { 2 - 5 } & 8 & 200 & 300 & 200 \\
\hline \multirow{3}{*}{3} & 1 & 400 & 300 & - \\
\cline { 2 - 5 } & 6 & 400 & - & - \\
\hline \multirow{2}{*}{4} & 11 & 400 & 300 & 200 \\
\cline { 2 - 5 } & 4 & 400 & 300 & 200 \\
\hline
\end{tabular}

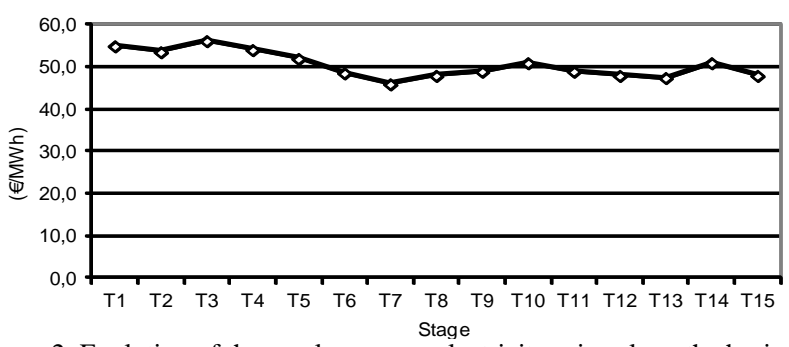

Figure 2. Evolution of the yearly average electricity price along the horizon.

\section{Impact of wind generation for different scenarios}

In a second step, we estimated the long term impact on the average electricity price of changing the wind power installed capacity. The results obtained along the 15 years in each case:

1. no wind power capacity - the average electricity market price is $56.8 € / \mathrm{MWh}$;

2. half of the wind capacity in 2010 - this reduces wind capacity to $11707.5 \mathrm{MW}$. The average price is reduced to $53.3 € / \mathrm{MWh}$;

3. wind capacity of 2010 - this case is similar to the one in Section B, that is, $23415 \mathrm{MW}$ of wind installed capacity. The average electricity price is $51.7 € / \mathrm{MWh}$;

4. wind capacity increased by $25 \%$ regarding 2010 - the average electricity price reduces to $47.2 € / \mathrm{MWh}$;

5. wind capacity increased by $50 \%$ regarding 2010 - the average electricity price reduces to $43.9 € / \mathrm{MWh}$.

Taking Case 4 , the results show that an increase of the wind capacity by $25 \%$ regarding the value in 2010 (more $5854 \mathrm{MW}$ ) reduces the average price by $4.5 € / \mathrm{MWh}$. Admitting a capacity factor of $25 \%$ for the wind parks, this new capacity generates $12.8 \mathrm{TWh}$. This means that each block of $2.85 \mathrm{TWh}$ of new wind generation regarding the amount in 2010 reduces the price by $1 € / \mathrm{MWh}$.

\section{CONCLUSIONS}

This paper detailed two approaches to quantify the impact of subsidized generation, in particular wind power, on the price of the Iberian Electricity Market. One of the approaches has a short term nature and directly uses the selling/buying market curves. Being a short term approach, the results are very much dependent on the period under analysis. The second approach uses a long term simulation model that provides more meaningful results, namely that each new block of $2.85 \mathrm{TWh}$ of wind generation decreases the market price by $1 € / \mathrm{MWh}$. These results and the possible calibration of a capacity term to be paid to thermal generators, are examples of how these models can be useful and can provide important insights to regulatory agencies or other decision makers.

\section{REFERENCES}

[1] A. J. C. Pereira, J. T. Saraiva, "A Decision Support Tool for Generation Expansion Planning in Competitive Markets using System Dynamics Models", in Proceedings of the IEEE PowerTech 2009 International Conference, Bucharest, Romania, 28 June - 2 July 2009.

[2] A. J. C. Pereira, J. T. Saraiva, "Generation Expansion Planning (GEP) - A Long-Term Approach Using System Dynamics and Genetic Algorithms (GAs)", Energy, vol. 36, no. 8, pp. 5180-5199, Aug. 2011.

[3] J. Sirikum, A. Techanitisawad, V. Kachitvichyanukul, "A New Efficient GA-Benders' Decomposition Method: For Power Generation Expansion Planning with Emission Controls", IEEE Transactions on Power Systems, vol. 22, no. 3, pp. 1092 - 1100, August 2007.

[4] B. G. Gorenstin, N. M Campodonico, J. P. Costa, M. V. Pereira, "Power System Expansion Planning Under Uncertainty", IEEE Transactions on Power Systems, vol. 8, no. 1, pp. 129-136, Feb. 1993.

[5] J. C. Meza, M. Yildrim, A. S. Masud, "A Model for the Multiperiod Multiobjective Power Generation Expansion Planning", IEEE Trans. on Power Systems, vol. 22, no. 2, pp. 871-878, May 2007.

[6] C. H. Antunes, A. G. Martins, I. Brito, "A Multiple Objective Mixed Integer Linear Programming Model for Power Generation Expansion Planning", Energy, vol. 29, no. 4, pp. 613-627, March 2004.

[7] J. Zhu, M. Chow, "A Review of Emerging Techniques on Generation Expansion Planning", IEEE Transactions on Power Systems, vol. 12, no. 4, pp. 1722-1728, November 1997.

[8] J.-B. Park, Y.-M. Park, J.-R. Won, K. Y. Lee, "An Improved Genetic Algorithm for Generation Expansion Planning", IEEE Transactions on Power Systems, vol. 15, no. 3, pp. 916 - 922, August 2000.

[9] M. Yildirim, K., Erkan, S. Ozturk, "Power Generation Expansion Planning with Adaptive Simulated Annealing Genetic Algorithm", International Journal of Energy Research, vol. 30, no. 14, pp. 1188 1199, October 2006.

[10] F. Wu, Z. Yen, Y. Hou, Y. Ni, "Applications of AI Techniques to Generation Planning and Investment", in Proceedings of the 2004 IEEE PES General Meeting, vol. 1, pp. 936 - 940, Denver, June 2004.

[11] J. Forrester, "System Dynamics and the Lessons of 35 Years", in The Systemic Basics of Policy Making in the 1990s, K. B. De Greene, Ed. Sloan School of Management, MIT, USA, April 1991.

[12] F. Olsina, F. Garces, H.-J. Haubrich, "Modelling Long-Term Dynamics of Electricity Markets", Energy Policy, vol. 34, no. 12, pp. 1411-1433, August 2006.

[13] T. Kadoya, T. Sasaki, S. Ihara, E. Larose, M. Sanford, A. K. Graham, C. A. Stephens, C. K. Eubanks, "Utilizing System Dynamics Modelling to Examine Impact of Deregulation on Generation Capacity Growth", in Proceedings of the IEEE, vol. 93, no. 11, pp. 2060 2069, November 2005.

[14] T. S. Jalal, P. Bodger, "The Development of a System Dynamics Model to Evaluate Generation Expansion in New Zealand", in Proceedings of AUPEC 2010, Australasian Universities Power Engineering Conference, Christchurch, New Zealand, Dec. 2010.

[15] Powersim Software AS, Powersim Studio 7 Academic, Powersim Software AS, Bergen, Norway, 2006. 